JURNAL KETAHANAN NASIONAL

Vol. 26, No. 1, April 2020, Hal 71-86

DOI:http://dx.doi.org/ 10.22146/jkn.53372

ISSN:0853-9340(Print), ISSN:2527-9688(Online)

Online sejak 28 Desember 2015 di :http://jurnal.ugm.ac.id/JKN

VOLUME 26

No. 1, April 2020

Halaman 71-86

\title{
Ketahanan Ekonomi Masyarakat Pesisir Di Kawasan Ekowisata Bahari Dusun Sendangbiru, Desa Tambakrejo, Kabupaten Malang, Provinsi Jawa Timur
}

\author{
Nuddin Harahab \\ Fakuktas Perikanan dan Ilmu Kelautan Universitas Brawijaya Malang, Indonesia \\ (Pascasarjana Multidisiplin, Group Riset: Ketahanan Berbasis Kemaritiman \\ dan Wilayah Perbatasan) \\ email: marmunnuddin@ub.ac.id

\section{Zainal Fanani} \\ Fakultas Peternakan Universitas Brawijaya Malang, Indonesia \\ (Pascasarjana Multidisiplin, Group Riset: Ketahanan Berbasis Kemaritiman \\ dan Wilayah Perbatasan) \\ email: prof_zaenalfanani@yahoo.co.id

\section{Dhiana Puspitawati} \\ Fakultas Hukum Universitas Brawijaya Malang, Indonesia \\ (Pascasarjana Multidisiplin, Group Riset: Ketahanan Berbasis Kemaritiman \\ dan Wilayah Perbatasan) \\ email: dhiana@ub.ac.id

\section{Abdullah Said} \\ Fakultas Ilmu Administrasi Universitas Brawijaya Malang, Indonesia \\ (Pascasarjana Multidisiplin, Group Riset: Ketahanan Berbasis Kemaritiman \\ dan Wilayah Perbatasan) \\ email: abdullahsa83@yahoo.co.id
}

\begin{abstract}
This study aims to describe the management system of coastal natural resources for ecotourism; to analyze the relationship between maritime ecotourism management and the economic resilience of coastal communities; and to analyze economic development and prosperity which to be seen from the four components used namely health, education, per capita expenditure and settlement. The approach in this study is qualitative in order to understand the phenomenon of maritime ecotourism management and its relation to the economic resilience of coastal communities. The data analysis of this research uses the Interactive Analysis Model, which includes: data condensation, data display, and conclusion: drawing / verifying. The results showed that the coastal natural resource management system for maritime ecotourism which was carried out by the Bhakti Alam Foundation, Sendangbiru, with the CMC (Clungup Mangrove Conservation) trade mark, has the good category by implementing ecotourism principles namely conservation, participation, recreation and education, economics, and control. Maritime Ecotourism management which was carried out by the Bhakti Alam Foundation, provides benefits for the availability of fish stocks in the sea,
\end{abstract}


although there are some people who have not recognized the benefits of mangrove forest conservation on capture fisheries productivity. Economic development and prosperity when to be seen from the four components, namely health, education, per capita expenditure and settlement, can be concluded that their condition were in the good category.

Keywords: Maritime Ecotourism, Clungup Mangrove Conservation, Economic Resilience, Coastal Communities.

\begin{abstract}
ABSTRAK
Penelitian ini bertujuan untuk mendeskripsikan sistem pengelolaan sumberdaya alam pesisir untuk ekowisata; menganalisis keterkaitan antara pengelolaan ekowisata bahari dengan ketahanan ekonomi masyarakat pesisir; dan menganalisis perkembangan perekonomian dan kemakmuran masyarakat pesisir yang dilihat dari empat komponen, yakni kesehatan, pendidikan, pengeluaran perkapita dan pemukiman. Pendekatan dalam penelitian ini bersifat kualitatif dengan maksud untuk memahami fenomena tentang pengelolaan ekowisata bahari dan keterkaitannya dengan ketahanan ekonomi masyarakat pesisir. Analisis data penelitian ini menggunakan model dari Miles, et al., yang disebut Analisis Data Model Interaktif, yang meliputi: kondensasi data (data condensation), penyajian data (data display), dan penarikan kesimpulan atau verifikasi (conclusion: drawing/verifying). Hasil penelitian menunjukkan bahwa sistem pengelolaan sumberdaya alam pesisir untuk ekowisata bahari yang dilakukan oleh Yayasan Bhakti Alam Sendangbiru, dengan trade mark CMC (Clungup Mangrove Conservation), termasuk dalam kategori baik dengan menjalankan prinsip ekowisata yaitu konservasi, partisipasi, rekreasi dan edukasi, ekonomi, dan control. Pengelolaan ekowisata bahari yang dilakukan oleh Yayasan Bhakti Alam Sendangbiru, memberikan manfaat bagi ketersediaan stok ikan yang ada di laut, meskipun masih ada sebagian orang yang belum mengakui manfaat dari konservasi hutan mangrove terhadap produktivitas perikanan tangkap. Perkembangan perekonomian dan kemakmuran apabila dilihat dari empat komponen, yakni kesehatan, pendidikan, pengeluaran perkapita dan pemukiman dapat disimpulkan dalam kondisi baik.
\end{abstract}

Keywords: Ekowisata Bahari, Clungup Mangrove Concervation, Ketahanan Ekonomi, Masyarakat Pesisir.

\section{PENGANTAR}

Ketahanan pangan merupakan ketahanan yang mencerminkan kehidupan dalam perekonomian bangsa, yang memiliki kemampuan menjaga stabilitas ekonomi yang sesuai, serta dapat memberikan kemandirian ekonomi nasional dengan daya saing tinggi dan mewujudkan kemakmuran rakyat yang adil dan merata (Cable, 1995). Dengan demikian, pembangunan ekonomi ditujukan ke arah ketahanan ekonomi dengan meciptakan iklim usaha yang tepat, memanfaatkan ilmu pengetahuan dan teknologi, penyediaan barang dan jasa, memelihara fungsi lingkungan hidup, serta meningkatkan daya saing dalam persaingan global (Pearce, Barbier, \& Markandya, 2013).

Dapat dikatakan bahwa ketahanan pangan merupakan sebuah sistem, yaitu rangkaian dari tiga komponen utama yang meliputi : ketersediaan dan stabilitas pangan (food availabilitydan stability), kemudahan memperoleh pangan (food accessibility) dan pemanfaatan pangan (Ariani, 2007; Godfray et al., 2010; Porter et al., 2017; Rosegrant \& Cline, 2003).

Ketersediaan dan stabilitas pangan khususnya di bidang perikanan, tentu berkaitan erat dengan sumberdaya alam dan lingkungannya. Dalam masyarakat pesisir lebih dari 50\% kebutuhan pangan tergantung dari sumberdaya alam dan lingungan sekitarnya. Penggerak ekonomi masyarakat pesisir mengandalkan dari komoditi ikan hasil tanggapan para nelayan. Ketersediaan dan stabilitas pangan ikan yang tinggi akan mendorong pergerakan ekonomi masyarakat, pertukaran produk dan jasa akan terjadi, 
Nuddin Harahab, Zainal Fanani, Dhiana Puspitawati, Abdullah Said -- Ketahanan Ekonomi Masyarakat Pesisir Di Kawasan Ekowisata Bahari Dusun Sendangbiru, Desa Tambakrejo, Kabupaten Malang, Provinsi Jawa Timur

keadaan seperti itu akan dirasakan oleh masyarakat bahwa ketahanan pangan bagi dirinya akan aman.

Perkembangan wisata bahari akan mengancam produktivitas perairan, jika mengabaikan faktor pendukung produktivitas perairan tersebut yaitu terumbu karang dan hutan mangrove (Harahab, 2010). Beberapa tahun terakhir ini ekosistem terumbu karang dan mangrove mendapatkan tekanan secara terus menerus akibat aktivitas manusia. Pertumbuhan penduduk yang sangat cepat membutuhkan berbagai sumberdaya untuk memenuhi kebutuhan hidupnya. Namun dalam memanfaatkannya sering kali kurang memperhatikan kelestarian sumberdaya alam tersebut, termasuk dalam hal ini adalah pengrusakan hutan mangrove. Perlu disadari bahwa peran fisik vegetasi mangrove adalah sebagai peredam ombak dan mencegah terjadinya abrasi. Bahkan pada ukuran diameter batang lebih dari $15 \mathrm{~cm}$, ketebalan lebih dari 200 meter dengan kerapatan 30 pohon per 100 meter, hutan mangrove mampu meredam energi gelombang stunami. Selain itu, hutan mangrove memberikan sumbangan yang sangat berarti untuk kesuburan perairan terkait dengan perputaran unsur hara bagi flora dan fauna. Hasil penelitian Harahab (2009) menunjukkan bahwa terdapat hubungan yang signifikan antara luasan hutan mangrove dengan produksi perikanan tangkap.

Pengelolaan hutan mangrove sebagai tempat wisata yaitu ekowisata mangrove, menjadi salah satu solusi tepat untuk melestarikan dan meintegrasikan berbagai manfaat dan kebutuhan. Ekowisata merupakan suatu kegiatan pariwisata dengan menerapkan wawasan berbasis lingkungan dan dalam pengembangannya sangat memperhatikan keseimbangan nilai-nilai menjaga lingkungan.
Oleh karena itu, Undang-undang dan peraturan pemerintah yang ada kebijakan pengembangan ekowisata dapat dilihat dari ruang lingkup kepentingannya dan selayaknya harus yaitu antara lain: (1) UU No.4 tahun 1982 tentang Ketentuan-ketentuan pokok Lingkungan Hidup; (2) UU No.5 tahun 1990 tentang Konservasi Sumberdaya Alam Hayati dan Ekosistem; (3) UU No.9 tahun 1990 tentang Kepariwisataan; (4) UU No.24 tahun 1992 tentang Penataan Ruang; (5) UU No.5 tahun 1994 tentang Ratifikasi Konservasi Keanekaragaman Hayati; (6) Peraturan Pemerintah No.13 tahun 1994 tentang Pengelolaan Alam di Zona Pemanfaatan kawasan Pelestarian; (7) Peraturan Pemerintah No. 67 tahun 1996 tentang Penyelenggaraan Kepariwisataan; (8) Keputusan bersama Menteri Kehutanan dan Menteri Parpostel No.24/KPTS-11/89 dan No.KM.1/UM.209/ MPPT-1998 tentang peningkatan koordinasi dua instansi tersebut untuk mengembangkan obyek wisata alam sebagai obyek daya tarik wisata.

Wilayah pesisir Kabupaten Malang diketahui memiliki potensi wisata bahari yang cukup tinggi (Satria, 2009). Salah satu destinasi wisata yang sangat cepat perkembangannya adalah ekowisata bahari Clungup Mangrove Conservation (CMC). Keberhasilan CMC dalam menjaga dan melestarikan terumbu karang dan hutan, khususnya keberadaan hutan di pantai Clungup merupakan bukti kepedulian masyarakat terhadap sumberdaya alam dan lingkungannya.

Sumberdaya alam dan lingkungan pesisir yang baik, akan berkonstribusi terhadap produktivitas hasil tangkapan nelayan, produktivitas nelayan yang tinggi dan kontinyu akan menentukan pergerakan ekonomi yang pada akhirnya akan menentukan ketahanan 
ekonomi masyarakat. Oleh karenanya, adakah keterkaitan yang nyata antara pengelolaan ekowisata bahari dengan ketahanan ekonomi keluarga. Menurut Euis (2003) bahwa ketahanan keluarga berarti kondisi dinamika sebuah keluarga yang memiliki keuletan dan ketangguhan serta mengandung kemampuan fisik dan material serta psikis dan mental spiritual, guna hidup mandiri mengembangkan diri dan keluarganya untuk hidup harmonis dalam meningkatkan kesejahteraan lahir dan kebahagiaan batin. Selanjutnya menurut penelitian Petiana, Iranto \& Wibowo, (2015), untuk menghitung perkembangan ekonomi dan kesejahteraan (kemakmuran) di Indonesia ada beberapa komponen yang digunakan yakni kesehatan, pendidikan, pengeluaran perkapita dan pemukiman.

Ketahanan ekonomi masyarakat adalah kondisi masyarakat yang mempunyai akses terhadap kecukupan pangannya, baik perorang ataupun kelompok mampu mempertahankan makanannya sepanjang waktu, baik secara fisik maupun secara ekonomi (Barrett, 2010; Carletto, Zezza, \& Banerjee, 2013; PinstrupAndersen, 2009). Komponen utama ketahanan pangan adalah ketersediaan dan stabilitas dalam aspek produksi. Pengertian ketersediaan adalah produksi yang dihasilkan; sedangkan pengertian stabilitas adalah kontinyuitas produksi (Rivera \& Qamar, 2003). Produksi dan kontinyuitas produksi perikanan tangkap (ikan) dipengaruhi oleh kualitas lingkungannya (Purnomo, 2018). Perkembangan ekowisata bahari khususnya ekowisata Clungup Mangrove Conservation yang semakin baik menunjukkan adanya perkembangan yang signifikan pada pertumbuhan terumbu karang, tutupan hutan lindung maupun hutan mangrove.

Permasalahan dalam penelitian ini terdiri dari tiga pertanyaan. Pertama, apakah perkembangan ekowisata bahari berpengaruh terhadap ketahanan ekonomi masyarakat pesisir? Kedua, bagaimana keterkaitan antara pengelolaan ekowisata bahari dengan ketahanan ekonomi? Ketiga, bagaimana perkembangan perekonomian dan kemakmuran apabila dilihat dari empat komponen, yakni kesehatan, pendidikan, pengeluaran perkapita dan pemukiman? Berdasarkan latar belakang dan permasalahan penelitian, maka tujuan penelitian ini adalah: mendeskripsikan sistem pengelolaan sumberdaya alam pesisir untuk ekowisata; menganalisis keterkaitan antara pengelolaan ekowisata bahari dengan ketahanan ekonomi masyarakat pesisir; dan menganalisis perkembangan perekonomian dan kemakmuran yang dilihat dari empat komponen, yakni kesehatan, pendidikan, pengeluaran perkapita dan pemukiman.

Penelitian ini dilakukan di Kabupaten Malang, Provinsi Jawa Timur, tepatnya di kawasan Ekowisata CMC (Clungup Mangrove Conservation) di Dusun Sendangbiru, Desa Tambakrejo, Kecamatan Sumbermanjing Wetan, Kabupaten Malang. Penelitian ini menggunakan data primer dan data sekunder untuk memperkuat terhadap analisis pada masalah yang telah dirumuskan.

Pendekatan dalam penelitian ini adalah bersifat kualitatif dengan maksud untuk memahami fenomena tentang pengelolaan ekowisata bahari dan keterkaitannya dengan ketahanan ekonomi masyarakat pesisir. Dijelaskan oleh Moleong (2008) dan Shkedi (2005) bahwa penelitian dengan pendekatan kualitatif dilakukan secara holistik dengan cara mendeskripsikan dalam bentuk kata-kata dan bahasa serta dianalisis secara induktif dengan membandingkan dengan teori yang relevan.

Informan dalam penelitian ini adalah mereka yang secara khusus memiliki 
Nuddin Harahab, Zainal Fanani, Dhiana Puspitawati, Abdullah Said -- Ketahanan Ekonomi Masyarakat Pesisir Di Kawasan Ekowisata Bahari Dusun Sendangbiru, Desa Tambakrejo, Kabupaten Malang, Provinsi Jawa Timur

pengetahuan dan informasi atas data yang ingin diperoleh. Informan awal penelitian ini dipilih secara purposive (purposive sampling) yaitu sampel sengaja dipilih oleh peneliti dengan pertimbangan yang sesuai dengan tujuan penelitian. Purposive sampling digunakan dalam penentuan informan kunci, selanjutnya penentuan informan yang lainnya dilakukan secara snowball berdasarkan petunjuk dari informan kunci (Robinson, 2014).

Metode analisis dalam penelitian ini menggunakan model interaktif. Proses penyusunan data dilakukan agar data mudah ditafsirkan. Penyusunan data berarti menggolongkan dalam pola, tema atau kategori. Analisis Data Model Interaktif meliputi: kondensasi data (data condensation), penyajian data (data display), dan penarikan kesimpulan atau verifikasi (conclusion: drawing/verifying). Model interaktif dalam analisis data ditunjukkan dalam Gambar 1.

Berdasarkan Gambar 1, langkahlangkah dalam penelitian ini dimulai dengan mengumpulkan data terlebih dahulu sebelum mengembangkan suatu teori atau membandingkan pola-pola yang ditemukan dengan teori-teori yang ada sebelumnya. Hasil penelitian ini kemudian disempurnakan dengan penyusunan proposisi. Proposisi dibangun berdasarkan data dan hasil analisis data serta pembahasan.

\section{PEMBAHASAN}

\section{Sistem Pengelolaan Sumberdaya Alam Pesisir Untuk Ekowisata}

Pada tahun 2012 dibentuk Kelompok Masyarakat Pengawas (POKMASWAS) GOAL yang diinisiasi oleh Dinas Kelautan dan Perikanan baik tingkat Kabupaten maupun Provinsi, dengan berpedoman pada UU 27 Tahun 2007 tentang Pengelolaan Wilayah Pesisir. POKMASWAS GOAL pada saat itu bekerja untuk mengembalikan hutan pesisir (greenbelt) yang sudah rusak akibat penebangan liar sekitar $117 \mathrm{Ha}$. Mereka merehabilitasi hutan mangrove seluas 81 $\mathrm{Ha}$, serta melakukan perlindungan terhadap terumbu karang di kawasan perairan Selat Sempu.

Jumlah anggota POKMASWAS GOAL pada awal berdirinya tahun 2012, ada sekitar 60 orang, tetapi kemudian menyusut hingga tinggal 6 orang yang bertahan. Hal ini disebabkan karena pengelolaan untuk melindungi sumberdaya di wilayah pesisir dilakukan secara sukarela dan tidak

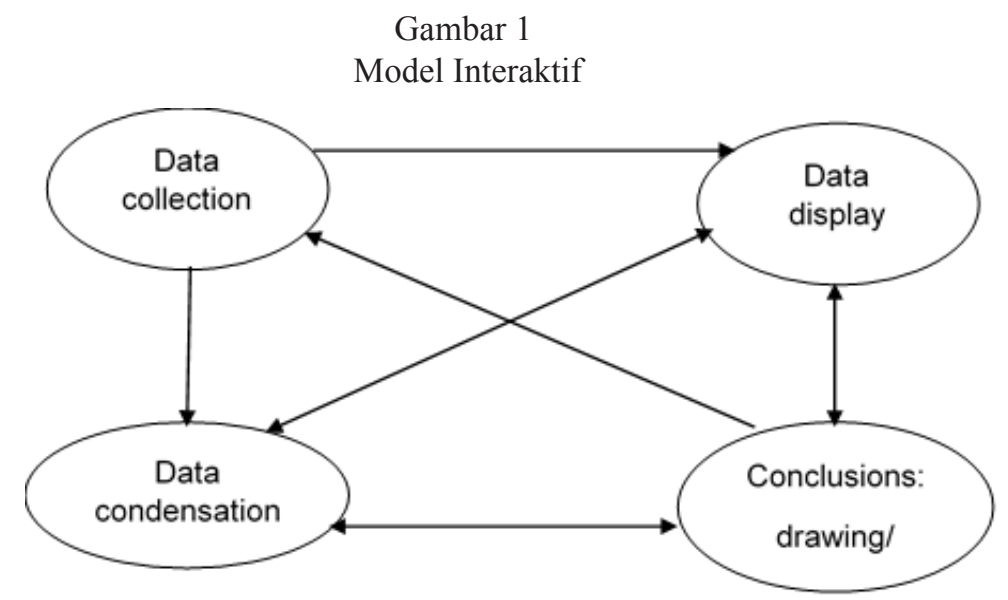

Sumber: Matthew B. Miles, et al., Qualitative Data Analysis: A Methods Sourcebook. Singapore: SAGE Publications Inc., 2014:33. 
mendapatkan bayaran atau gaji. Dengan 6 orang yang bertahan, pengelolaan tetap berjalan dengan baik yang meliputi kegiatan restorasi hutan mangrove yang sudah rusak, penanaman kembali di area hutan lindung yang sudah gundul akibat penebangan liar, kegiatan transplantasi terumbu karang serta pengawasan wilayah pesisir dari kegiatan penangkapan ikan yang dikategorikan tidak ramah lingkungan.

Pada tahun selanjutnya kegiatan dari masyarakat ini berupa pengabdian secara sukarela dari masyarakat untuk melindungi Kawasan Marine Protected Area (MPA) meliputi hutan mangrove, hutan pantai, pantai, padang lamun, muara, dan juga terumbu karang yang ada di kawasan pesisir Sendangbiru. Volunteer yang tergabung dalam kegiatan pengabdian yang terhimpun dalam POKMASWAS GOAL akhirnya membentuk sebuah lembaga yang bernama Yayasan Bhakti Alam Sendangbiru pada tahun 2014 yang bergerak untuk mengelola kawasan konservasi dengan visi "Hidup Bersama Alam". Adapun misinya ialah "membangun masyarakat yang cinta lingkungan, membentuk masyarakat desa konservasi, memanfaatkan sumberdaya alam secara bertanggung jawab melalui program pemberdayaan masyarakat, serta berpartisipasi aktif dalam pengembangan desa wisata di Jawa Timur".

\section{Keterkaitan Antara Pengelolaan Ekowisata CMC Tiga Warna Dengan Ketahanan Ekonomi Masyarakat Pesisir}

Ekowisata adalah pariwisata yang berwawasan lingkungan, melalui aktivitas berkaitan dengan alam, melihat menikmati dan mencintai alam. Ada beberapa padanan yang sering digunakan antara lain: natural-based tourism, green travel, responsible travel, low impact tourism, village based tourism, sustainable tourism, cultural tourism, heritage tourism, rural tourism (Angulo-Valdés, 2007; Gale \& Hill, 2016). Berdasarkan data yang didapatkan di lapangan ternyata masih banyak nelayan yang kurang mengetahui tentang adanya pengelolaan ekowisata CMC Tiga Warna yang dilakukan oleh Yayasan Bhakti Alam Sendangbiru. Memang ada sebagian kecil nelayan yang sudah mengetahui tentang pengelolaan dan manfaat CMC Tiga Warna terkait dengan perikanan tangkap. Patut disayangkan dan cukup memprihatinkan bahwa nelayan yang hidupnya tergantung dengan keberadaan ikan di laut, tetapi mereka kurang menyadari pentingnya menjaga ekosistem pesisir misalnya ekosistem terumbu karang, hutan mangrove, dan hutan yang nonmangrove.

Ketahanan ekonomi masyarakat pesisir (nelayan) sangat tergantung pada keberadaan ikan. Sementara itu, keberadaan ikan sangat tergantung dengan keberadaan terumbu karang, hutan mangrove serta hutan nonmangrove atau hutan pesisir sebagai greenbelt. Terdapat hubungan sebab akibat antara ikan dan lingkungannya, yang sebagai buktinya dapat dilihat dan dibandingkan keadaan sekitar tahun 2010 dan tahun 2018. Sebenarnya para nelayan sudah merasakan akibat yang terjadi di sekitar tahun 2010, saat terjadi kerusakan ekosistem hutan, serta keadaan sekitar tahun 2018 setelah keberhasilan rehabilitasi hutan. Akan tetapi para nelayan masih belum menyadari akan hal itu. Kebanyakaan masyarakat pesisir tidak mengakui adanya hubungan yang positif dan nyata antara populasi ikan dengan keberadaan hutan di kawasan pesisir. Hasil penelitian Harahab (2009) menyatakan bahwa semakin tinggi luasan hutan mangrove semakin tinggi hasil 
Nuddin Harahab, Zainal Fanani, Dhiana Puspitawati, Abdullah Said -- Ketahanan Ekonomi Masyarakat Pesisir Di Kawasan Ekowisata Bahari Dusun Sendangbiru, Desa Tambakrejo, Kabupaten Malang, Provinsi Jawa Timur

tangkapan nelayan. Respon masyarakat terkait dengan pengelolaan Clungup Mangrove Conservation (CMC) dapat dilihat pada Gambar 2.

Gambar 2

Respon Masyarakat Nelayan terhadap Pengelolaan Ekowisata (CMC)

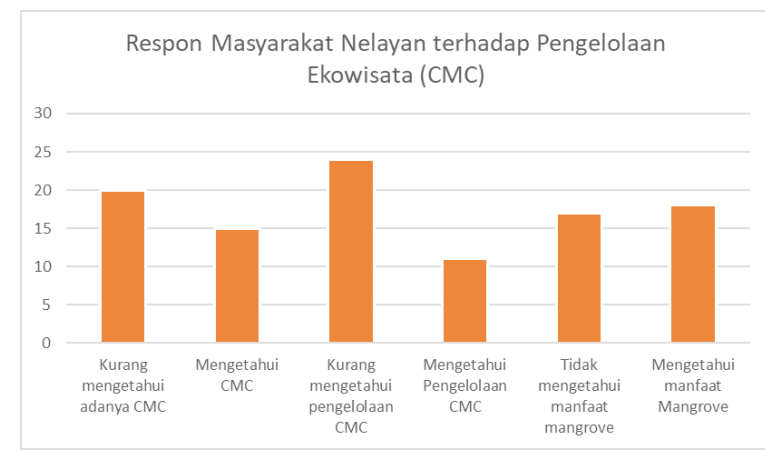

Sumber: Data survey 2019

Dari gambar tersebut, sebanyak 24 orang nelayan kurang mengetahui tentang pengelolaan yang dilakukan di kawasan CMC Tiga Warna. Rata-rata mereka tidak mengetahui pengelolaan di CMC Tiga Warna karena mereka hanya fokus untuk bekerja melaut mencari ikan agar dapat memenuhi kebutuhan sehari-hari buat keluarga mereka, seperti kebutuhan pangan pokok, kebutuhan sampingan, kebutuhan biaya pendidikan, kebutuhan biaya kesehatan, maupun kebutuhan biaya untuk perbaikan rumah. Namun di antara 24 orang, masih ada sekitar 10 orang yang mengakui bahwa mangrove di pesisir pantai Clungup mempunyai manfaat dan memberikan dampak positif bagi para nelayan terutama dilihat dari hasil tangkapan mereka seharihari. Menurut mereka mangrove bermanfaat sebagai rumah ikan, tempat berkembangbiak ikan, serta sebagai penahan abrasi. Didukung dengan pernyataan Duke, Nagelkerken, Agardy, Wells \& Van Lavieren (2014) bahwa mangrove mempunyai peran besar bagi lingkungan, yang salah satunya adalah sebagai tempat hidup berbagai macam biota laut untuk berlindung dan mencari makan.

Jika dilihat dari hubungan antara pengelolaan ekowisata dengan ketahanan ekonomi masyarakat pesisir, bisa dikatakan keluarga nelayan berkecukupan dalam kebutuhan ekonomi mereka. Dengan kata lain, keberhasilan pengelolaan ekowisata memiliki hubungan yang kuat dengan ketahanan ekonomi masyarakat pesisir. Dengan demikian, pengelolaan ekowisata bahari yang dilakukan oleh Yayasan Bhakti Alam Sendangbiru, tentunya memberikan manfaat bagi ketersediaan stok ikan yang ada di laut, meskipun masih ada sebagian orang yang belum mengakui manfaat dari konservasi hutan mangrove terhadap produktivitas perikanan tangkap. Perlu adanya lahan konservasi terhadap hutan mangrove dalam rangka penjagaan dan pelestarian hutan agar fungsifungsi mangrove dapat dioptimalkan sebaik mungkin (Donato, Kauffman, Mackenzie, Ainsworth, \& Pfleeger, 2012; Lugo, Medina, \& McGinley, 2014; Sandilyan \& Kathiresan, 2012).

\section{Perkembangan Perekonomian dan Kemakmuran Masyarakat Pesisir}

Deskripsi dan analisis tentang perkembangan perekonomian dan kemakmuran masyarakat pesisir dalam penelitian ini dilihat dari empat komponen sebagai berikut.

\section{Kesehatan}

Kesehatan merupakan suatu kebutuhan yang sangat penting bagi masyarakat (Thompson, Kreuter \& Boyum, 2016). Penduduk dengan tingkat kesehatan yang baik merupakan masukan (input) penting untuk menurunkan kemiskinan, pertumbuhan ekonomi, dan pembangunan ekonomi dalam 
waktu yang lama. Sejarah membuktikan bahwa keberhasilan pertumbuhan ekonomi yang meningkat tinggi sangat didukung oleh inovasi penting di bidang kesehatan masyarakat, pencegahaan penyakit dan perbaikan gizi (Organization, 2002). Berdasarkan data yang didapatkan di lapang, semua responden menyatakan dirinya sehat, setelah didata konsisi keseharan selama 3 bulan terakhir hanya ada 1 orang pernah sakit hingga tidak bisa kerja selama beberapa hari, selebihnya 7 orang sakit ringan seperti flu dan pilek, dan yang lain selama 3 bulan terkhir tidak sakit, ilusterasi kondisi kesehatan masyarakat dalam Gambar 3.

Masyarakat di Desa Tambakrejo sudah mampu menyisihkan pendapatan mereka untuk di keperluan kesehatan. Ketika nelayan atau keluarga sakit yang cukup ringan seperti batuk atau flu, mereka lebih memilih untuk membeli obat yang dijual di warung-warung kelontong dekat rumah mereka. Apabila nelayan itu sendiri atau keluarga mereka sedang sakit, dan ketika sakit yang cukup parah mereka akan memilih untuk pergi periksa ke puskesmas terdekat atau rumah sakit terdekat. Biasanya mereka memilih untuk pergi ke puskesmas di
Sitiarjo, Sumbermanjing, Kabupaten Malang, karena puskesmas di Desa Tambakrejo (dekat dengan TPI) tidak selalu buka 24 jam serta kurangnya tenaga medis yang ahli. Apabila dan seandainya sudah periksa ke puskesmas Sitiarjo, namun tidak dapat ditangani oleh pihak puskesmas, maka mereka biasanya akan di rujuk ke rumah sakit besar di Kota Malang. Biasanya keluarga nelayan di rujuk ke Rumah Sakit Umum Saiful Anwar atau Rumah Sakit Lavalatte di Kota Malang. Fasilitas, sumber daya manusia, dan jarak rumah hingga rumah sakit menentukan seseorang untuk berobat (Bankart et al., 2011).

\section{Pendidikan}

Pendidikan dalam kaitannya dengan perekonomian secara nasional, semakin tinggi kualitas hidup suatu bangsa, maka akan semakin tinggi tingkat pertumbuhan dan kesejahteraan bangsa tersebut. Semakin tinggi tingkat pendidikan masyarakat maka akan semakin tinggi produktivitasnya dan dengan demikian juga akan semakin tinggi pertumbuhan ekonomi suatu negara (Nugroho, 2016). Secara umum tingkat pendidikan penduduk Desa Tambakrejo belum tinggi,

Gambar 3.

Kondisi Kesehatan Masyarakat

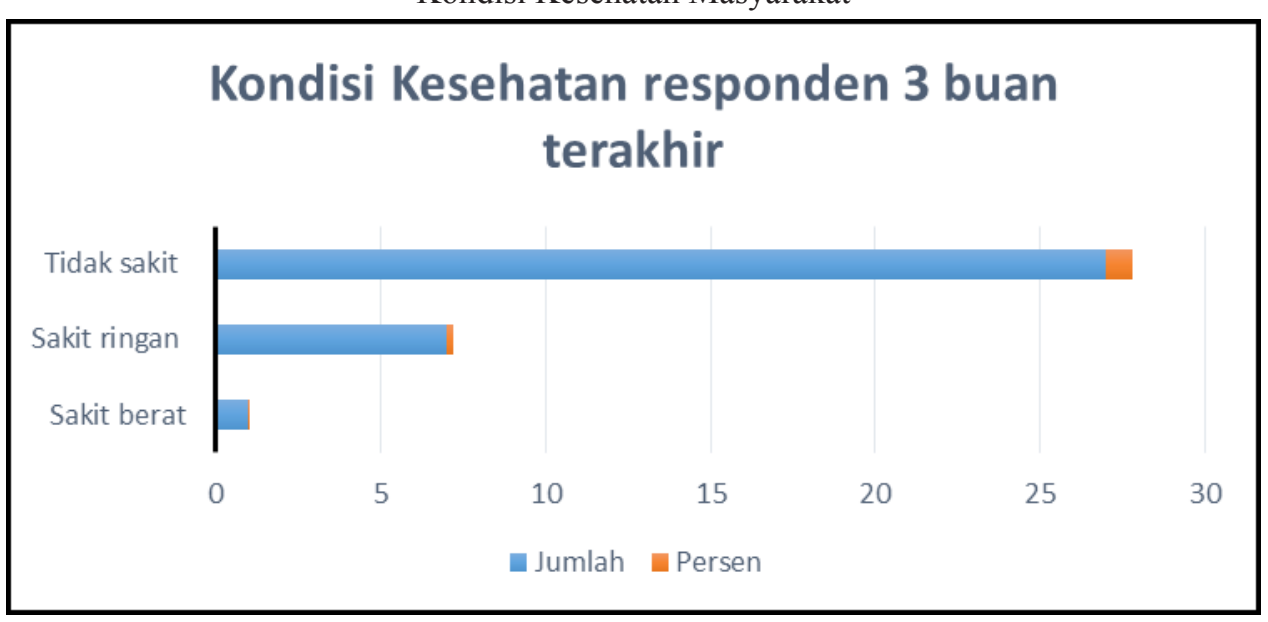

Sumber: Data survey 2019. 
Nuddin Harahab, Zainal Fanani, Dhiana Puspitawati, Abdullah Said -- Ketahanan Ekonomi Masyarakat Pesisir Di Kawasan Ekowisata Bahari Dusun Sendangbiru, Desa Tambakrejo, Kabupaten Malang, Provinsi Jawa Timur

yakni sebagian besar masih berada di tingkat Pendidikan Sekolah Dasar. Data masyarakat berdasarkan lulusan pendidikan dapat dilihat pada Tabel 1

Tabel 1

Penduduk Desa Tambakrejo Berdasarkan Tingkat Pendidikan

\begin{tabular}{llcc}
\hline No. & Pendidikan & $\begin{array}{c}\text { Jumlah } \\
\text { (jiwa) }\end{array}$ & $\begin{array}{c}\text { Persentase } \\
(\mathbf{\%})\end{array}$ \\
\hline 1. & Tamat TK & 395 & 6,1 \\
2. & Tamat SD & 3.938 & 61,2 \\
3. & Tamat SLTP & 1.202 & 18,7 \\
4. & Tamat SLTA & 855 & 13,3 \\
5. & Tamat Sarjana & 45 & 0,7 \\
\hline & Total & $\mathbf{6 . 4 3 5}$ & $\mathbf{1 0 0}$ \\
\hline
\end{tabular}

Sumber: Monografi Desa Tambakrejo, 2017

Menurut sensus penduduk pada tahun 2017, jumlah penduduk desa Tambakrejo sebanyak 6.435 jiwa. Sebagian besar penduduk desa Tambakrejo memiliki pendidikan terakhir di tingkat Sekolah Dasar (SD). Sebagaian kecil sekitar 0,7 persen memiliki pendidikan terakhir di tingkat Sarjana.

Tingkat pendidikan responden berdasarkan data survey lapangan, terdapat 35 responden sebagai nelayan. Sebagian besar para nelayan memiliki tingkat pendidikan terakhir di tingkat SD dengan jumlah 30 orang. Sisanya, sebanyak 4 orang nelayan memiliki pendidikan terakhir di tingkat SMP dan 1 orang nelayan memiliki pendidikan terakhir di tingkat SMA. Pendidikan terakhir istri para nelayan juga rata-rata di tingkat SD, yaitu sebanyak 23 orang. Sebanyak 7 orang memiliki pendidik terakhir SMP. Sisanya, sebanyak 3 orang memiliki pendidikan terakhir di tingkat SMA dan 2 orang lagi tidak bersekolah. Berikut adalah tingkat pendidikan suami istri dari 35 responden dalam bentuk diagram Gambar 3a dan Gambar 3b.

Walaupun para nelayan berpendidikan rendah, mereka berfikir bahwa anak-anak mereka harus berpendidikan lebih tinggi dari pada orang tuanya. Hampir semua nelayan responden manyatakan bahwa anaknya harus berpendidikan lebih tinggi dari orang tuanya. Di dukung dengan pernyataan bahwa semua orang tua meninginkan anaknya mendapatkan pendidikan yang tinggi (Bhardwaj, 2016). Mereka pun menyisihkan atau menabungkan pendapatan merekauntuk pendidikan anak, ketika mereka mendapatkan pendapatan yang lebih, selalu disisihkan untuk tabungan pendidikan.

Gambar 4b.

Tingkat Pendidikan istri

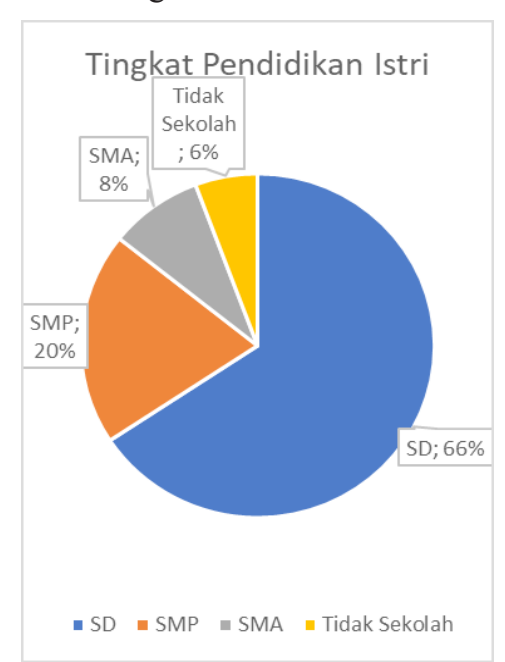

Sumber: Data survey 2019 
Apabila mereka mendapatkan pendapatan yang pas-pasan, mereka tidak akan menyisihkan pendapatan mereka, karena pendapatan yang didapatkan hanya cukup untuk kebutuhan pokok makan. Hasil di lapangan menunjukkan bahwa rata-rata anak-anak dari responden nelayan berada di jenjang sekolah dasar (SD), 1 orang di jenjang sekolah menengah pertama (SMP), dan 1 orang di jenjang diploma. Adanya program sekolah gratis dari pemerintah, sangat membantu para nelayan untuk menyekolahkan anakanaknya sampai ke jenjang sekolah menengah pertama (SMP).

\section{Pengeluaran Perkapita}

Permasalahan utama yang umum terjadi di negara berkembang dalam meningkatkan pembangunan ekonomi yaitu masalah mengenai penghasilan yang kurang serta kemiskinan. Dengan demikian dalam tujuan pembangunan ekonomi rendahnya penghasilan dan kemiskinan selalu dinyatakan bersamaan sehingga menjadi satu kalimat yaitu peningkatan pendapatan nasional dan pengurangan kemiskinan (De Janvry \& Sadoulet, 2010). Pengeluaran perkapita merupakan biaya yang dikeluarkan perorangan untuk konsumsi selama sebulan baik yang berasal dari pembelian, pemberian maupun produksi. Secara garis besar tingkat pengeluaran perkapita nelayan Dusun Sendangbiru dapat dikelompokkan menjadi tiga tingkat: rendah, sedang, dan tinggi, seperti disajikan dalam Gambar 4.

Berdasarkan data lapangan, pengeluaran perkapita nelayan di Sendangbiru dapat dijelaskan dalam tiga tingkatan sebagai berikut:

Pertama, Tingkat pengeluaran perkapita rendah, dilihat dari pengeluaran pokok yang pas-pasan (hanya cukup untuk makan 3 kali
Gambar 5

Tingkat pengeluaran perkapita nelayan Sendangbiru

Tingkat Pengeluaran Perkapita Nelayan Sendangbiru

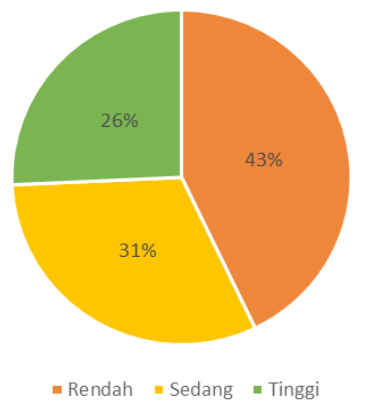

Sumber: Data survey, 2019

sehari) dan tidak dapat mengeluarkan biaya untuk pengeluaran sampingan.

Kedua, Tingkat pengeluaran perkapita sedang, dilihat dari pengeluaran pokok seharihari cukup untuk makan 3 kali sehari dan pengeluaran sampingan (bisa membeli tapi tidak setiap bulan atau hanya seperlunya saja tergantung ada pendapatan lebih atau tidak).

Ketiga, Tingkap pengeluaran perkapita tinggi, dilihat dari pengeluaran pokok seharihari sudah lebih dari cukup dan pengeluaran sampingan (bisa membeli barang kebutuhan primer, sekunder, dan tersier tanpa harus menunggu memiliki pendapatan lebih), sebagian dari hasil pendapatan dapat digunakan untuk menabung.

Berdasarkan diagram Gambar 4, masih banyak nelayan dengan tingkat pengeluaran perkapita rendah, dengan rata-rata penghasilan mereka di bawah Rp 1 juta dalam sekali trip (melaut), sehingga hanya cukup untuk makan sehari-hari. Sedangkan para nelayan dengan tingkat pengeluaran perkapita sedang, memperoleh pendapatan dalam satu kali trip rata-rata sebesar Rp 2,5 juta. Nelayan dalam kategori pengeluaran sedang biasanya lebih memilih untuk mencukupi kebutuhan pokok pangan mereka, sedangkan pendapatan sisanya 
Nuddin Harahab, Zainal Fanani, Dhiana Puspitawati, Abdullah Said -- Ketahanan Ekonomi Masyarakat Pesisir Di Kawasan Ekowisata Bahari Dusun Sendangbiru, Desa Tambakrejo, Kabupaten Malang, Provinsi Jawa Timur

digunakan untuk keperluan pendidikan anak mereka (jika anak masih sekolah) atau untuk keperluan perabotan rumah maupun sandang mereka. Nelayan pada tingkat pengeluaran perkapita tinggi, mampu memenuhi kebutuhan pokok pangan, kebutuhan sandang serta papan mereka sehingga mereka bisa melakukan saving (menabung) tetapi dengan jumlah yang tidak banyak dan tidak sering. Pendapatan peorangan merupakan upah, gaji, laba, tunjangan, dan ongkos yang di terima sesorang untuk kebutuhan sehari-hari. Jika memiliki kelebihan seseorang akan menyimpan sisa tabungannya untuk pendidikan, dana darurat, dan kesehatan (Babones, 2008; Dynan, Edelberg, \& Palumbo, 2009).

\section{Pemukiman}

Pemukiman dipakai sebagai salah satu ukuran kesejahteraan rumah tangga. Kondisi rumah, bentuk rumah, dan bahan pembuatan rumah menjadi indikator sejahtera. Kesejahteraan merupakan pencerminan dari kualitas hidup manusia (quality of human life). Menurut UU RI No. 11 tahun 2009, kesejahteraan sosial adalah situasi yang mampu memenuhi kebutuhan material, spiritual atau agama, dan sosial warga negara untuk dapat hidup yang sesuai atau makmur dan bisa mengupgrade diri.

Menurut Badan Koordinasi Keluarga Berencana Nasional (BKKBN) (2011), jenjang Keluarga Sejahtera dikategorikan dalam lima tahapan, yaitu Pra Sejahtera, Keluarga Sejahtera I, Keluarga Sejahtera II, Keluarga Sejahtera III dan Keluarga Sejahtera III Plus. Suatu keluarga dikatakan masuk kategori Pra Sejahtera apabila keluarga tersebut tidak sesuai dengan beberapa dari 6 indikator Keluarga Sejahtera I. Suatu keluarga bisa masuk ke Keluarga Sejahtera I apabila keluarga tersebut memenuhi 6 indikator akan tetapi tidak tidak dengan 8 indikator di Keluarga Sejahtera II. Suatu keluarga masuk ke katagori Keluarga Sejahtera II apabila keluarga tersebut memenuhi 6 indikator dari Keluarga Sejahtera I dan 8 indikator dari Keluarga Sejahtera II tetapi tidak memenuhi salah satu dari 5 indikator Keluarga Sejahtera III. Suatu keluarga masuk ke katagori Keluarga Sejahtera III apabila keluarga tersebut memenuhi 6 indikator dari Keluarga Sejahtera I, 8 indikator dari Keluarga Sejahtera II dan 5 indikator dari Keluarga Sejahtera III akan tetapi tidak dengan beberapa 2 indikator Keluarga Sejahtera III Plus. Suatu keluarga dapat dikatakan masuk Keluarga Sejahtera III Plus apabila keluarga tersebut memenuhi semua indicator dari Keluarga Sejahtera I sampai Keluarga Sejahtera III Plus. Rincian tahapan dan indikator kesejahteraan menurut BKKBN dapat dilihat pada Tabel 2

Hasil survei lapang masyarakat Dusun Sendangbiru berdasarkan ukuran kesejahteraan BKKBN lebih dari 50\% termasuk tahap sejahtera III. Ilusterasi secara grafis dapat dilihat pada Gambar 5.

Gambar 6

Kondisi Kesejahteraan Nelayan Sendangbiru

Kondisi Kesejahteraan Nelayan Sendangbiru

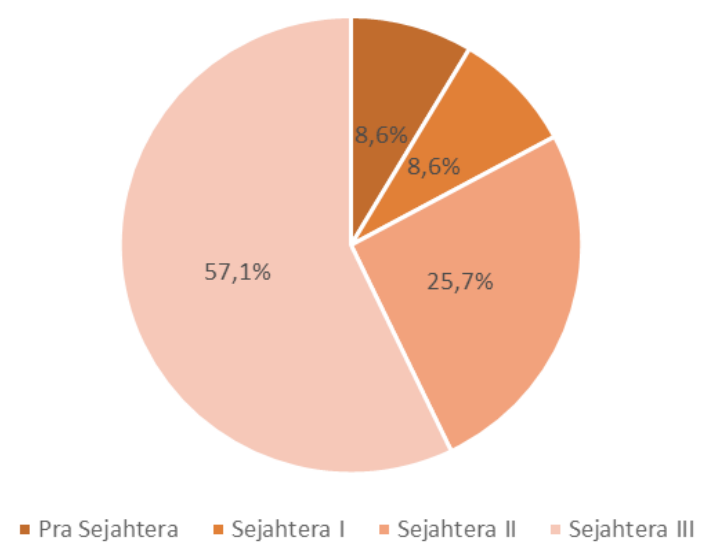

Sumber: Data survey, 2019 
Table 2

Indikator Tahapan Keluarga Sejahtera

\begin{tabular}{|c|c|c|}
\hline No & $\begin{array}{c}\text { Tahapan Keluarga } \\
\text { Sejahtera } \\
\end{array}$ & Indikator \\
\hline 1 & $\begin{array}{l}\text { Keluarga Sejahtera } \\
\text { I }\end{array}$ & $\begin{array}{l}\text { 1. Pada umumnya anggota keluarga makan dua kali sehari atau lebih } \\
\text { 2. Anggota keluarga memiliki pakaian yang berbeda untuk di rumah, bekerja/sekolah } \\
\text { dan berpergian } \\
\text { 3. Rumah yang ditempati keluarga mempunyai atap, lantai dan dinding yang baik } \\
\text { 4. Bila ada anggota keluarga sakit dibawa ke sarana kesehatan } \\
\text { 5. Bila pasangan usia subur ingin ber-KB pergi ke sarana pelayanan kontrasepsi } \\
\text { 6. Semua anak umur 7-15 tahun dalam keluarga bersekolah }\end{array}$ \\
\hline 2 & $\begin{array}{l}\text { Keluarga Sejahtera } \\
\text { II }\end{array}$ & $\begin{array}{l}\text { 1. Pada umumnya anggota keluarga melaksanakan ibadah sesuai dengan agama dan } \\
\text { kepercayaan masing-masing } \\
\text { 2. Paling kurang sekali seminggu seluruh anggota keluarga makan daging/ikan/telur } \\
\text { 3. Seluruh anggota keluarga memperoleh paling kurang satu stel pakaian baru dalam } \\
\text { setahun } \\
\text { 4. Luas lantai rumah paling kurang } 8 \mathrm{~m} 2 \text { untuk setiap penghuni rumah } \\
\text { 5. Tiga bulan terakhir keluarga dalam keadaan sehat sehingga dapat melaksanakan } \\
\text { tugas/fungsi masing-masing } \\
\text { 6. Ada seorang atau lebih anggota keluarga yang bekerja untuk memperoleh } \\
\text { penghasilan } \\
\text { 7. Seluruh anggota keluarga umur } 10-60 \text { tahun bisa baca tulisan latin } \\
\text { 8. Pasangan usia subur dengan anak dua atau lebih menggunakan alat/obat } \\
\text { kontrasepsi }\end{array}$ \\
\hline 3 & $\begin{array}{l}\text { Keluarga Sejahtera } \\
\text { III }\end{array}$ & $\begin{array}{l}\text { 1. Keluarga berupaya meningkatkan pengetahuan agama } \\
\text { 2. Sebagian penghasilan keluarga ditabung dalam bentuk uang atau barang } \\
\text { 3. Kebiasaan keluarga makan Bersama paling kurang seminggu sekali dimanfaatkan } \\
\text { untuk berkomunikasi } \\
\text { 4. Keluarga ikut dalam kegiatan masyarakat di lingkungan tempat tinggal } \\
\text { 5. Keluarga memperoleh informasi dari surat kabar/majalah/radio/tv/internet }\end{array}$ \\
\hline 4 & $\begin{array}{l}\text { Keluarga Sejahtera } \\
\text { III Plus }\end{array}$ & $\begin{array}{l}\text { 1. Keluarga secara teratur dengan suka rela memberikan sumbangan materiil untuk } \\
\text { kegiatan social } \\
\text { 2. Ada anggota keluarga yang aktif sebagai pengurus perkumpulan sosial/Yayasan/ } \\
\text { institusi masyarakat }\end{array}$ \\
\hline
\end{tabular}

Berdasarkan data yang didapatkan dan observasi di lapang, berikut indikator pemukiman rumah nelayan di Sendangbiru yang telah kami simpulkan, mengacu pada tabel indikator diatas:

Pertama, pra Sejahtera, lantai rumah masih beralaskan tanah dan tembok rumah masih terbuat dari triplek atau anyaman bambu.

Kedua, sejahtera 1, lantai rumah sudah terbuat dari semen dan tembok rumah terbuat dari batu bata.

Ketiga, sejahtera 2, lantai rumah sudah terbuat dari semen dan tembok rumah sudah terbuat dari semen.
Keempat, sejahtera 3, lantai rumah sudah berkeramik dan tembok rumah sudah di cat dengan rapi.

Ketika mereka mendapatkan pendapatan yang lebih banyak dari kebutuhan pokok mereka, para nelayan menganggarkan atau menabungkan pendapatan mereka untuk memperbaiki rumah mereka dengan cara membeli bahan-bahan bangunan sedikit demi sedikit sehingga mereka bisa memperbaiki rumah mereka sedikit-sedikit. Terdapat pula rumah nelayan yang di bangun oleh anaknya yang sudah sukses, sehingga rumahnya cukup layak untuk dihuni dan masuk ke kelompok 
Nuddin Harahab, Zainal Fanani, Dhiana Puspitawati, Abdullah Said -- Ketahanan Ekonomi Masyarakat Pesisir Di Kawasan Ekowisata Bahari Dusun Sendangbiru, Desa Tambakrejo, Kabupaten Malang, Provinsi Jawa Timur

Sejahtera II. Tetapi, ada juga rumah yang masuk ke kelompok Sejahtera III karena mendapatkan warisan dari kedua orang tuanya, sehingga nelayan tersebut tidak perlu menabung untuk biaya perbaikan rumah.

Nelayan juga mempunyai waktu untuk keluarga, selanjutnya jika terjadi bencana atau perayaan desa nelayan dengan senang hati membantu baik secara materiil dan jasanya dengan asas gotong royong mulai dari bersih desa, perayaan kenegaraan, sampai petik laut (acara adat). Banyak beberapa nelayan yang memiliki alat komunkasi untuk mengakses informasi dan berkomunikasi dengan keluarga maupun sesama nelayan.

Nelayan memang kebanyakan masuk dalam kategori kelompok sejahtera II akan tetapi condong ke kategori kelompok sejahtera III dengan banyak pertimbangan di atas meskipun tidak banyak. Banyaknya kebersamaan dan gotong royong nelayan membuat nelayan hidup rukun dan sejahtera. Pada dasarnya rumah layak huni memiliki manfaat yang besar untuk masyarakat itu sendiri. Manfaat terbesar dengan memiliki rumah layak huni yakni datangnya kenyamanan dalam menjalankan kehidupan sehari-hari. Dengan adanya kenyamanan, tentunya kehidupan dalam berkeluarga menjadi tentram, rukun, aman, dan Bahagia (Lyles-Chockley, 2008). Ekowisata dan kesejahteraan masyarakat sekitar khususnya nelayan sangat menyatu yang berdampak pada ketahanan pangan masyarakat sekitar yang bagus serta pro dengan lingkungan tanpa merusak alam dan masyarakat sejahtera dengan upaya konservasi dan gotong royong. Ekowisata dan kesejahteraan masyarakat adalah komponen yang saling terkait untuk memajukan perekonomian di daerah tersebut dengan perlindunag ekosistem di dalamnya baik manusianya maupun alam (Das \& Hussain, 2016; Situmorang \& Mirzanti, 2012; Snyman, 2013).

\section{SIMPULAN}

Hasil penelitian ini dapat disimpulkan bahwa:

Pertama, sistem pengelolaan sumberdaya alam pesisir untuk ekowisata bahari dilakukan oleh Yayasan Bhakti Alam, dengan trade mark CMC (Clungup Mangrove Conservation). Sistem pengelolannya termasuk dalam kategori baik, dengan menjalankan prinsip ekowisata yaitu konservasi, partisipasi, rekreasi dan edukasi, ekonomi, dan control.

Kedua, pengelolaan ekowisata bahari yang dilakukan oleh Yayasan Bhakti Alam Sendangbiru, memberikan manfaat bagi ketersediaan stok ikan yang ada di laut, meskipun masih ada sebagian orang yang belum mengakui manfaat dari konservasi hutan mangrove terhadap produktivitas perikanan tangkap.

Ketiga, perkembangan perekonomian dan kemakmuran masyarakat pesisir Sendangbiru dilihat dari empat komponen yang digunakan yakni kesehatan, pendidikan, pengeluaran perkapita dan pemukiman dapat disimpulkan dalam kondisi baik serta mendukung ketahanan ekonomi masyarakat sekitar.

\section{DAFTAR PUSTAKA}

Angulo-Valdés, J. A. (2007). Ecotourism and marine protected areas: A possible synergy to achieve the sustainable tourism paradigm in the insular Caribbean. Ocean Yearbook Online, 21(1), 339-363.

Ariani, M. (2007). Penguatan ketahanan pangan daerah untuk mendukung 
ketahanan pangan nasional. Pusat Analisis dan Kebijakan Pertanian. Bogor.

Babones, S. (2008). Income inequality and population health: correlation and causality. Social science \& medicine, 66(7), 1614-1626.

Bankart, M., Baker, R., Rashid, A., Habiba, M., Banerjee, J., Hsu, R., Wilson, A. (2011). Characteristics of general practices associated with emergency admission rates to hospital: a crosssectional study. Emergency Medicine Journal, 28(7), 558-563.

Barrett, C. B. (2010). Measuring food insecurity. Science, 327(5967), 825-828.

Bhardwaj, A. (2016). Importance of education in human life: A holistic approach. International Journal of Science Consciousness, 2(2), 23-28.

Cable, V. (1995). What is international economic security? International Affairs, 71(2), 305-324.

Carletto, C., Zezza, A., \& Banerjee, R. (2013). Towards better measurement of household food security: Harmonizing indicators and the role of household surveys. Global food security, 2(1), 30-40.

Das, D., \& Hussain, I. (2016). Does ecotourism affect economic welfare? Evidence from Kaziranga National Park, India. \%J Journal of Ecotourism, 15(3), 241-260.

De Janvry, A., \& Sadoulet, E. (2010). Agricultural growth and poverty reduction: Additional evidence. The World Bank Research Observer, 25(1), 1-20.

Donato, D. C., Kauffman, J. B., Mackenzie, R. A., Ainsworth, A., \& Pfleeger, A. (2012). Whole-island carbon stocks in the tropical Pacific: Implications for mangrove conservation and upland restoration. Journal of environmental management, 97, 89-96.

Duke, N., Nagelkerken, I., Agardy, T., Wells, S., \& Van Lavieren, H. (2014). The importance of mangroves to people: A call to action: United Nations Environment Programme World Conservation Monitoring Centre ....

Dynan, K. E., Edelberg, W., \& Palumbo, M. G. (2009). The effects of population aging on the relationship among aggregate consumption, saving, and income. American Economic Review, 99(2), 380-386.

Gale, T., \& Hill, J. (2016). Ecotourism and environmental sustainability: An introduction. In Ecotourism and Environmental Sustainability (pp. 2134): Routledge.

Godfray, H. C. J., Beddington, J. R., Crute, I. R., Haddad, L., Lawrence, D., Muir, J. F., ... Toulmin, C. (2010). Food security: the challenge of feeding 9 billion people. science, 327(5967), 812-818.

Harahab, N. (2009). Pengaruh ekosistem Hutan Mangrove Terhadap Produksi Perikanan Tangkap (Studi Kasus di Kabupaten Pasuruan, Jawa Timur). Jurnal Perikanan Universitas Gadjah Mada, 11(1), 100-106.

Harahab, N. (2010). Penilaian ekonomi ekosistem hutan mangrove \& aplikasinya dalam perencanaan wilayah pesisir: Graha Ilmu.

Lugo, A. E., Medina, E., \& McGinley, K. (2014). Issues and challenges of mangrove conservation in the Anthropocene. Madera y Bosques, 20(1), 11-38. 
Nuddin Harahab, Zainal Fanani, Dhiana Puspitawati, Abdullah Said -- Ketahanan Ekonomi Masyarakat Pesisir Di Kawasan Ekowisata Bahari Dusun Sendangbiru, Desa Tambakrejo, Kabupaten Malang, Provinsi Jawa Timur

Lyles-Chockley, A. (2008). Building Livable Places: The Importance of Landscape in Urban Land Use, Planning, and Development. \%J Buff. Envtl. LJ, 16, 95.

Moleong, L. (2008). Metodologi Penelitian Kualitatif edisi revisi Bandung: PT Remaja Rosdakarya Offset.

Nugroho, S. (2016). Pengaruh Pendidikan Terhadap Pertumbuhan Ekonomi. Media Ekonomi dan Manajemen, 29(2).

Organization, W. H. (2002). The work of WHO in the South-East Asia Region: Report of the Regional Director 1 July 2001-30 June 2002. Retrieved from

Pearce, D., Barbier, E., \& Markandya, A. (2013). Sustainable development: economics and environment in the Third World: Routledge.

Petiana, I., Iranto, D., \& Wibowo, A. (2015). Tingkat Pendidikan Tenaga Kerja, Pengeluaran Pemerintah Sektor Pendidikan, dan Pertumbuhan Ekonomi di Indonesia Tahun 2008-2012. Jurnal Pendidikan Ekonomi Dan Bisnis (JPEB), 3(1), 51-80.

Pinstrup-Andersen, P. (2009). Food security: definition and measurement. Food security, 1(1), 5-7.

Porter, J. R., Xie, L., Challinor, A. J., Cochrane, K., Howden, S. M., Iqbal, M. M., . . . Dokken, D. (2017). Food security and food production systems.

Purnomo, B. H. (2018). SKKD No. 969/ UN25. 5.1/TU. 3/2017" Peranan Perikanan Tangkap Berkelanjutan Untuk Menunjang Ketahanan Pangan di Indonesia".

Rivera, W. M., \& Qamar, M. K. (2003). Agricultural extension, rural development and the food security challenge: Food and Agriculture
Organization of the United Nations Rome.

Robinson, O. C. (2014). Sampling in interviewbased qualitative research: A theoretical and practical guide. Qualitative research in psychology, 11(1), 25-41.

Rosegrant, M. W., \& Cline, S. A. (2003). Global food security: challenges and policies. Science, 302(5652), 1917-1919.

Sandilyan, S., \& Kathiresan, K. (2012). Mangrove conservation: a global perspective. Biodiversity and Conservation, 21(14), 3523-3542.

Satria, D. (2009). Strategi pengembangan ekowisata berbasis ekonomi lokal dalam rangka program pengentasan kemiskinan di wilayah Kabupaten Malang. Journal of Indonesian Applied Economics, 3(1).

Sharma, G. (2017). Pros and cons of different sampling techniques. International journal of applied research, 3(7), 749752.

Shkedi, A. (2005). Multiple case narrative: A qualitative approach to studying multiple populations (Vol. 7): John Benjamins Publishing.

Situmorang, D. B. M., \& Mirzanti, I. R. (2012). Social entrepreneurship to develop ecotourism. \%J Procedia Economics Finance, 4, 398-405.

Snyman, S. (2013). Household spending patterns and flow of ecotourism income into communities around Liwonde National Park, Malawi. \%J Development Southern Africa, 30(4-5), 640-658.

Thompson, T., Kreuter, M. W., \& Boyum, S. (2016). Promoting health by addressing basic needs: effect of problem resolution on contacting health referrals. Health Education \& Behavior, 43(2), 201-207. 


\section{Peraturan Perundangan}

Undang-Undang No.24, tahun 1992 tentang Penataan Ruang. Diperbanyak oleh Direktorat Tata Kota dan Tata Daerah, Direktorat Jenderal Cipta Karya, Departemen Pekerjaan Umum.

Undang-Undang No.9, tahun 1990 tentang Kepariwisataan. Presiden Republik Indonesia.

Undang-Undang No.4, Tahun 1982 tentang Ketentuan-ketentuan Pokok Pengelolaan Lingkungan Hidup. Jakarta: Kantor Menteri Negara Pembangunan dan Lingkungan Hidup.

Undang-Undang No.5, tahun 1990 tentang Konservasi Sumberdaya Alam Hayati dan Ekosistem.
Undang-Undang No.5, tahun 1994 tentang Ratifikasi Konservasi Keanekaragaman Hayati.

Peraturan Pemerintah No.13 tahun 1994 tentang Pengelolaan Alam di Zona Pemanfaatan kawasan Pelestarian.

Peraturan Pemerintah No. 67 tahun 1996 tentang Penyelenggaraan Kepariwisataan.

Keputusan bersama Menteri Kehutanan dan Menteri Parpostel No.24/KPTS-11/89 dan No.KM.1/UM.209/MPPT-1998 tentang peningkatan koordinasi dua instansi tersebut untuk mengembangkan obyek wisata alam sebagai obyek daya tarik wisata. 